\title{
An extension of the acceptance model of intuitive eating in adolescent girls: a role for social comparison?
}

\author{
Rachel Andrew*, Marika Tiggemann, Levina Clark \\ From 2014 ANZAED Conference: Driven Bodies Driven Brains \\ Fremantle, Australia. 22-23 August 2014
}

Intuitive eating (i.e., eating in response to internal cues) has been shown to be negatively related to disordered eating in women. The acceptance model of intuitive eating proposes that intuitive eating results from increased body appreciation, lowered self-objectification and body acceptance by others. As yet, this model has not been tested in adolescent girls; a group vulnerable to eating pathology. In addition to testing the acceptance model in adolescent girls, this study aimed to examine the role of social comparison. Participants were 400 girls aged 12 to 16 years who completed questionnaire measures of perceived body acceptance by others, social comparison, self-objectification, body appreciation and intuitive eating. In support of the model, perceived body acceptance and body appreciation correlated positively with intuitive eating, while selfobjectification and social comparison correlated negatively. Structural Equation Modeling showed the extended acceptance model was an acceptable to good fit to the data. In particular, the effects of perceived body acceptance were mediated by self-objectification and social comparison. The findings replicate the acceptance model of intuitive eating in adolescent girls, but also indicate that social comparison is important in this process. Practically, the findings highlight several areas that may be targeted to foster adaptive eating patterns in girls.

This abstract was presented in the Prevention \& Public Health stream of the 2014 ANZAED Conference.

Published: 24 November 2014

* Correspondence: rachel.andrew@flinders.edu.au

School of Psychology, Flinders University, Adelaide, Australia
doi:10.1186/2050-2974-2-S1-040

Cite this article as: Andrew et al: An extension of the acceptance model of intuitive eating in adolescent girls: a role for social comparison? Journal of Eating Disorders 2014 2(Suppl 1):040.
Submit your next manuscript to BioMed Central and take full advantage of:

- Convenient online submission

- Thorough peer review

- No space constraints or color figure charges

- Immediate publication on acceptance

- Inclusion in PubMed, CAS, Scopus and Google Scholar

- Research which is freely available for redistribution
() Biomed Central 